\title{
A Case of Cochlear Implantation in Bromate-Induced Bilateral Sudden Deafness
}

\author{
Tae-Ho Eom, Sungsu Lee, Hyong-Ho Cho, and Yong-Beom Cho \\ Department of Otolaryngology-Head and Neck Surgery, Chonnam National University Medical School, Gwangju, Korea
}

\author{
Received June 18, 2014 \\ Revised November 15, 2014 \\ Accepted November 25, 2014
}

\section{Address for correspondence}

Hyong-Ho Cho, MD, PhD

Department of Otolaryngology-

Head and Neck Surgery,

Chonnam National University

Medical School,

42 Jebong-ro, Dong-gu,

Gwangju 501-757, Korea

Tel $+82-62-220-6776$

Fax +82-62-228-7743

E-mailvvictocho@hanmail.net
Despite the well-established nature of bromate-induced ototoxicity, cochlear implantation after bromate intoxication has been rarely documented. We hereby present a case of a 51 -yearold female deafened completely after bromate ingestion. Her hearing was not restored by systemic steroid treatment and hearing aids were of no use. A cochlear implantation was performed on her right ear 3 months after the bromate ingestion. In bromate intoxication cases, early monitoring of hearing level is necessary and other drugs with potential ototoxicity should be avoided. The outcome of cochlear implantation was excellent in this case of bromate-induced deafness.

J Audiol Otol 2015;19(1):51-53

KEY WORDS: Sodium bromate · Potassium bromate · Ototoxicity · Deafness · Cochlear implantation.

\section{Introduction}

Sodium bromate and potassium bromate are strong oxidants that are widely used in hair permanent wave neutralizers, reagents of printing or dyeing and other chemical processes. Hair wave permanent neutralizing solutions typically contain $2-10 \%$ sodium or potassium bromate, which are colorless, odorless and tasteless $[1,2]$. Bromate can cause clinical problems when ingested, accidentally or deliberately for suicide.

Clinical manifestations of bromate intoxication include vomiting, diarrhea, central nervous system symptoms, oliguric or non-oliguric acute renal failure, hemolytic anemia, and deafness [1-3]. All but kidney injury and deafness are reversible. Hearing impairment is rather common and is usually rapidly progressive, bilateral, and of severe to profound sensorineural type of hearing loss (SNHL) [3,4]. Although many investigators have studied the characteristics of hearing impairment, cochlear implantation (CI) after bromate intoxication has been rarely documented [5-7]. We hereby present a case of success-

This is an Open Access article distributed under the terms of the Creative Commons Attribution Non-Commercial License (http://creativecommons. org/licenses/by-nc/3.0/) which permits unrestricted non-commercial use, distribution, and reproduction in any medium, provided the original work is properly cited. ful CI in bromate-induced bilateral sudden total deafness.

\section{Case Report}

A 51-year-old female was referred to our hospital for bromate intoxication. She had accidentally ingested a cold wave neutralizer. Within one hour after the ingestion, she developed nausea, vomiting, and diffuse abdominal pain. Her past history included hypertension, left hemiparesis due to previous brain hemorrhage and infarction and depressive disorder. Upon arrival in the emergency room of a local hospital, she received intravenous hydration and furosemide injection. One day later, she was referred to our hospital with decreased urinary output and reduced mental state. Hemodialysis was initiated under the diagnosis of acute renal failure. Four days after admission, her kidney function was normalized and mentality was recovered to an alert state.

Soon after mental recovery, she complained about bilateral hearing impairment. She did not have a history of hearing problems before the bromate ingestion. Pure tone audiometry (PTA) showed total SNHL in both ears (Fig. 1A). The auditory steady state response threshold was $100 \mathrm{~dB}$ (Fig. 1B) and Vwave was not detectable at $90 \mathrm{~dB}$ in the auditory brainstem re- 


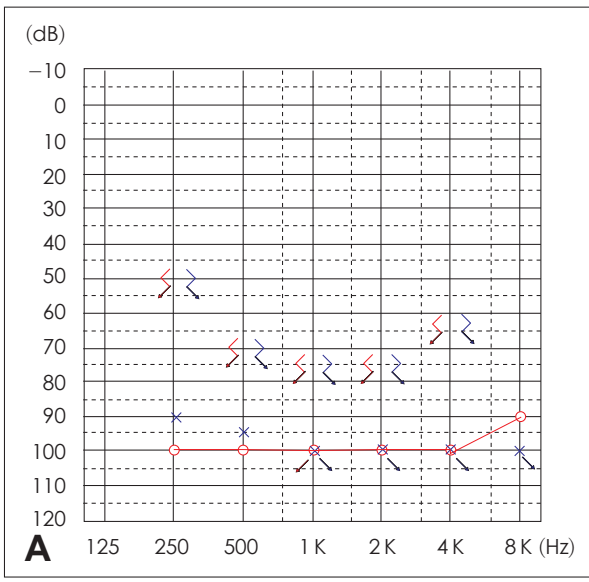

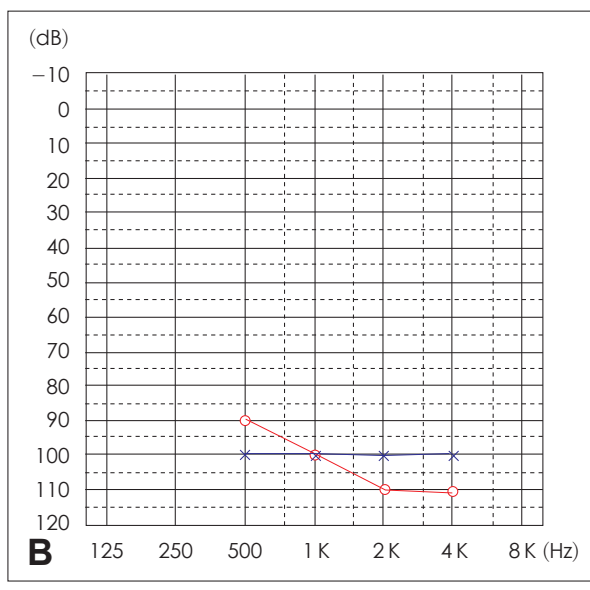

Fig. 1. Preoperative pure tone audiometry (A) and auditory steady-state response (B) showed near total deafness in both ears.
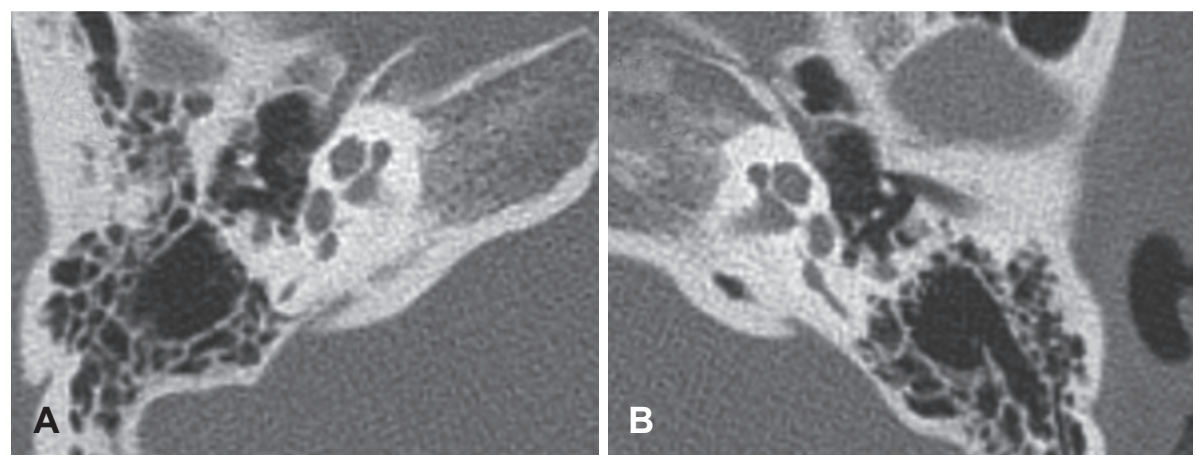

Fig. 2. Preoperative temporal bone $C T$ of the right $(A)$ and left $(B)$ ear. Anatomical structure of the inner ear was normal.
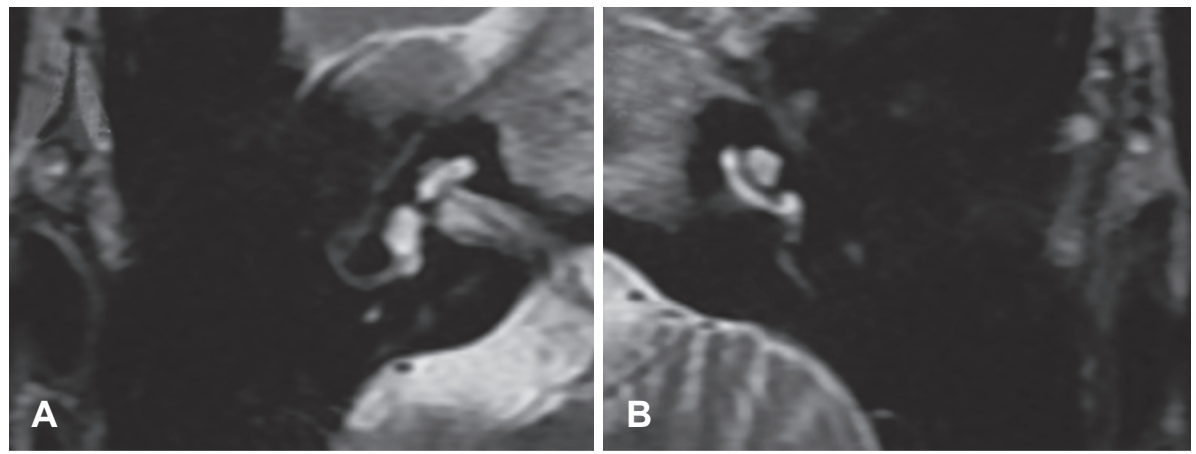

Fig. 3. Preoperative MRI T2-weighted image of the right (A) and left (B) ear demonstrating normal high signal intensity of cochlear and vestibuocochlear nerves.

sponse. Temporal bone computed tomography (Fig. 2) and magnetic resonance imaging (Fig. 3) showed normal inner ear structure on both sides. She was diagnosed as having bromate-induced sudden deafness and steroid was administered systematically for a week with tapering for another week.

However, her hearing did not recover until 3 months after the ingestion. A CI was performed on her right ear. Nucleus 24RE was implanted without any intra-operative problems and the neural response telemetry showed satisfactory values. The postoperative period was uneventful. Post-operative $\mathrm{X}$-ray revealed successful electrode insertion in the cochlear turn. The first fitting of the device was done one month after the operation. Preoperatively, all her comprehension tests were
0\%. Six months after the implant, CI-aided PTA showed a threshold of $30 \mathrm{~dB}$ (Fig. 4A). In auditory only condition, she comprehended $70 \%$ of the sentences, $85 \%$ of the words and $68 \%$ in the Korean version of the Central Institute for the Deaf test. Categories of auditory performance score rose from 3 preoperatively to 6 points (Fig. 4B).

\section{Discussion}

Hearing problems may be diagnosed with a delay after bromate intoxication due to other life-threatening symptoms such as acute renal failure which generally occurs within 1 hour after the ingestion. However, the onset of bromate-induced 


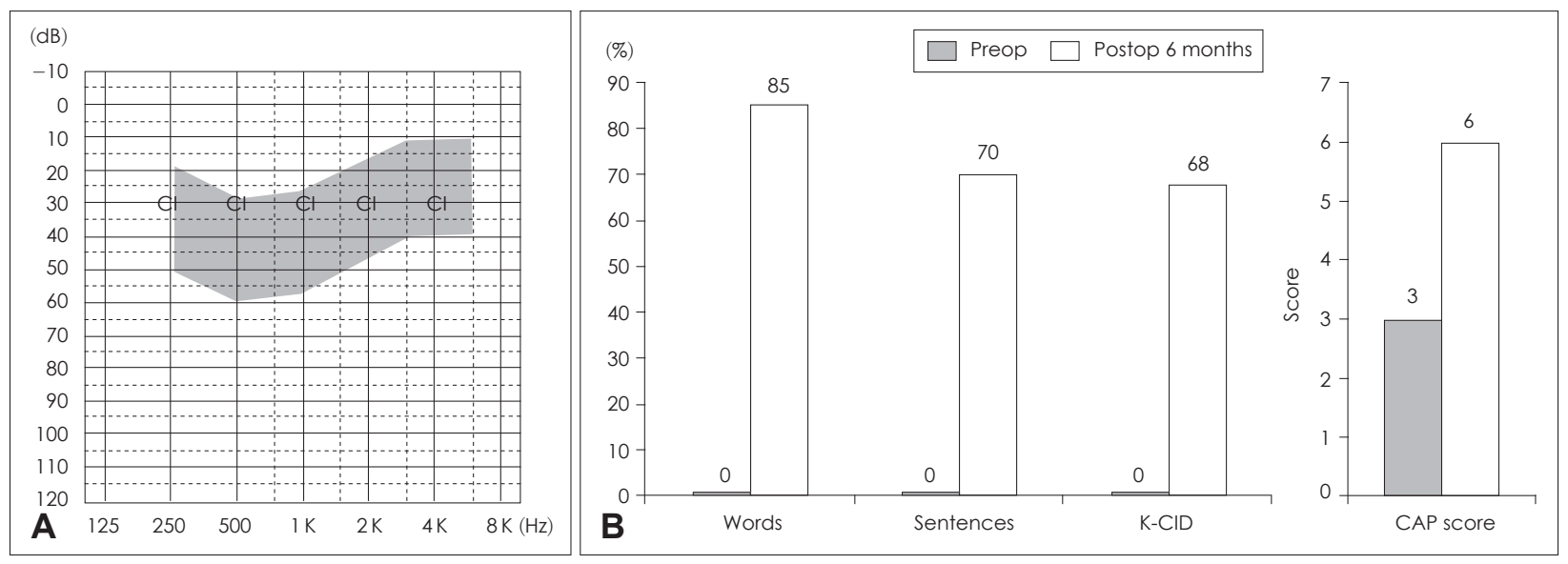

Fig. 4. $\mathrm{A}: \mathrm{Cl}$-aided pure tone audiometry at 6 months postoperatively showing threshold of $30 \mathrm{~dB}$. $\mathrm{B}$ : Auditory performance scores were markedly improved 6 months after the implantation. Cl: cochlear implantation, K-CID: Korean version of the Central Institute for the Deaf, CAP: categories of auditory performance.

hearing loss is actually rapid, occurring within 4-16 hours of ingestion $[3,4,7]$. Like many other ototoxins, hearing loss is of the sensorineural type with no middle or external ear involvement $[3,8,9]$. The degree of hearing impairment is severe to profound, and is irreversible in most cases.

There have been some treatment strategies to decrease other toxic effects of bromate [1-4]. For example, furosemide has been recommended to improve renal function. Since they are usually transient, loop diuretics including furosemide are ototoxic in themselves [2]. In the present case, the patient received furosemide during the primary treatment, which may have aggravated the ototoxic effects of bromate. Caution should be exercised when furosemide is used in cases of bromate intoxication.

The mechanisms underlying bromated-induced ototoxicity have not been fully determined. Previous studies using guinea pigs and sodium bromate demonstrated severe collapse of the Reissner's membrane, hair cell degeneration and damage of the stria vascularis $[8,9]$. The ototoxicity may be ascribed to a decrease in enzyme activities which leads to damage of the stria vascularis with degenerative changes in outer hair cells. A breakdown of the endolymph-perilymph barrier may also be responsible [8,9].

On the other hand, dizziness associated with bromated-induced vestibulotoxicity is not common. If dizziness manifests, it is usually non-specific instead of true vertigo. The dizziness could be secondary to other systemic toxicities such as lightheadedness or general malaise [4].

To our knowledge, there has only been one report in the English literature of CI performed in patients deafened due to bromated-ingestion [7]. In this case, the diagnosis of hearing loss was delayed for at least 6 months after bromate inges- tion. In our case, deafness was diagnosed right after the recovery of consciousness and the intervention with CI was done 3 months after the diagnosis. In both cases, the outcome of CI was good.

Sodium or Potassium bromate may cause acute irreversible profound sensorineural hearing loss. Other potential drugs with ototoxicity should be avoided and early monitoring of hearing level is needed. CI may be useful in patients with bromate-induced deafness.

\section{REFERENCES}

1) Ryu DH, Jang KA, Kim SM, Park JW, Do JY, Yoon KW. Acute kidney injury due to sodium bromate intoxication: a report of two cases. Korean J Intern Med 2011;26:463-5.

2) Sashiyama H, Irie Y, Ohtake Y, Nakajima K, Yoshida H, Sakai T, et al. Acute renal failure and hearing loss due to sodium bromate poisoning: a case report and review of the literature. Clin Nephrol 2002;58: 455-7.

3) Campbell KC. Bromate-induced ototoxicity. Toxicology 2006;221: 205-11.

4) Quick CA, Chole RA, Mauer M. Deafness and renal failure due to potassium bromate poisoning. Arch Otolaryngol 1975;101:494-5.

5) Nichani J, Bruce IA, Mawman D, Khwaja S, Ramsden R, Green K. Cochlear implantation in patients deafened by ototoxic drugs. Cochlear Implants Int 2013;14:207-12.

6) Torkos A, Czigner J, Kiss JG, Tóth F, Szamosközi A, Jóri J. Cochlear implantation for treatment-induced ototoxic deafness in Langerhans cell histiocytosis. A case report. Eur Arch Otorhinolaryngol 2005; 262:496-500.

7) Tono T, Ushisako Y, Morimitsu T, Takenaka M. Cochlear implants in deafened patients due to potassium bromate poisoning. Adv Otorhinolaryngol 1997;52:315-7.

8) Matsumoto I. Clinical and experimental studies on the ototoxicity of bromate. Otol Fukuoka 1973;19:220-36.

9) Muratsuka Y, Ueda H, Konishi T. Effects of sodium bromate on ionic concentrations and osmolalities of the cochlear fluids in guinea pigs. Hear Res 1989;39:241-9. 